Abstract

\title{
Beyond Nutrients: Insights for Health Professionals around a Communal Iftar Meal during Ramadan ${ }^{\dagger}$
}

\author{
Abduraouf Ibrahim ${ }^{1}$, Marwa Khalifa ${ }^{1}$, Heather Came ${ }^{2}$ and Carolyn Cairncross ${ }^{3, *}$ \\ 1 School of Public Health, Auckland University of Technology, Auckland 1142, New Zealand; \\ kikio500020@yahoo.com (A.I.), kiko500020@yahoo.com (M.K.) \\ 2 Taupua Waiora Centre for Māori Health Research, Auckland University of Technology, Auckland 1142, \\ New Zealand; heather.came@aut.ac.nz \\ 3 School of Sport and Recreation, Auckland University of Technology, Auckland 1142, New Zealand \\ * Correspondence: carolyn.cairncross@aut.ac.nz \\ + Presented at the 2018 Nutrition Society of New Zealand Annual Conference, Auckland, New Zealand, 28- \\ 30 November 2018.
}

Published: 13 March 2019

Background: Two main meals are consumed by Muslims during Ramadan, before sunrise (Suhoor), and after sunset (Iftar). The AUT Mosque is an integrated, multi-ethnic place of worship, providing a free communal Iftar meal for the Muslim community, feeding 200-300 people nightly. The meal is primarily meat and white rice, with a small salad, and is catered by external providers. The study aim was to gather perceptions of members of AUT Mosque around the Iftar meal.

Method: Ten men and eight women of the AUT Mosque took part in four gender-specific focus groups during Ramadan in June 2018. Qualitative data was analysed using thematic analysis using positivist and interpretive frameworks.

Results: Participation in Ramadan and the Iftar meal positively impacts spiritual and holistic health. Findings of this study were gendered, with women showing a greater interest and knowledge around nutrition, making suggestions for healthier Iftar meals. Conversely, males focused on food type, quantity and taste of the Iftar meal. The communal meal acted as a conduit for social interaction and celebration.

Conclusion: The spiritual and celebratory nature of food consumed in the AUT Mosque Iftar meal moves the focus beyond nutrient intake. This study highlights the challenge of tapping into nutrition expertise and resources of women whilst respecting cultural dynamics. The Iftar meal may present an opportunity to strengthen women's voices as well as improving the health status of the Mosque community. In addition, this communal meal during Ramadan presents as a critical opportunity to establish relationships, and to conduct a public health intervention around food with the Muslim community.

(C) 2019 by the authors. Licensee MDPI, Basel, Switzerland. This article is an open access article distributed under the terms and conditions of the Creative Commons Attribution (CC BY) license (http://creativecommons.org/licenses/by/4.0/). 